\title{
Rapamycin Regulates iTreg Function through CD39 and Runxl Pathways
}

\author{
Yunjie Lu, Jirong Wang, Jian Gu, Hao Lu, Xiangcheng Li, Xiaofeng Qian, \\ Xiaoshan Liu, Xuehao Wang, Feng Zhang, and Ling Lu
}

Translational Medicine Research Center of Jiangning Hospital and Liver Transplantation Center of First Affiliated Hospital, Nanjing Medical University, Nanjing 210029, China

Correspondence should be addressed to Feng Zhang; zhangf@njmu.edu.cn and Ling Lu; linglu@njmu.edu.cn

Received 25 January 2014; Revised 25 February 2014; Accepted 5 March 2014; Published 31 March 2014

Academic Editor: Xiuli Wu

Copyright (c) 2014 Yunjie Lu et al. This is an open access article distributed under the Creative Commons Attribution License, which permits unrestricted use, distribution, and reproduction in any medium, provided the original work is properly cited.

It has been shown that rapamycin is able to significantly increase the expression of FoxP3 and suppress activity in induced Treg (iTreg) cells in vivo and in vitro. CD39 is a newly determined Treg marker that relates to cell suppression. Runxl, a regulator of FoxP3, controls the expression of adenosine deaminase (ADA) gene, which is found recently in the downstream of CD39 pathway in trophoblast cells. Whether rapamycin would influence CD39 pathway and regulate the expression of Runx1 remains to be determined. The addition of rapamycin to human $\mathrm{CD} 4^{+}$naïve cells in the presence of IL-2, TGF- $\beta$ promotes the expression of FoxP3. In this paper, we found that CD39 positively correlated with the FoxP3 expression in iTreg cells. Rapamycin induced iTreg cells showed a stronger CD39/Runx1 expression with the enhanced suppressive function. These data suggested that CD39 expression was involved in iTreg generation and the enhanced suppressive ability of rapamycin induced Treg was partly due to Runxl pathway. We conclude that rapamycin favors CD39/Runxl expression in human iTreg and provides a novel insight into the mechanisms of iTreg generation enhanced by rapamycin.

\section{Introduction}

$\mathrm{CD} 4^{+} \mathrm{CD} 25^{+} \mathrm{FoxP}^{+}$regulatory $\mathrm{T}$ cells (Treg) play an essential role in maintaining immunological homeostasis. Forkhead box P3 transcription factor (FoxP3) is responsible for the differentiation and function of Treg cells [1]. CD $4^{+}$FoxP $3^{+} \mathrm{T}$ cells show a greater suppressive ability and immune function than normal $\mathrm{T}$ cells in vivo and in vitro. $\mathrm{CD} 4^{+}$Foxp $3^{+} \mathrm{T}$ cells can be divided into two subsets, thymus-derived natural regulatory $\mathrm{T}$ cells (nTreg) and induced Treg cells (iTreg). In clinical trials, the major limitation of nTreg is the poor population of peripheral circulating $\mathrm{CD} 4{ }^{+} \mathrm{T}$ cells, while iTreg shows a good alternative to nTreg with a greater proliferative ability [2]. iTreg can be induced from naïve $\mathrm{CD} 4^{+} \mathrm{CD} 25^{-}$ $\mathrm{T}$ cells in both mice and human. Recently reports have shown that iTreg plays an important role in treating various autoimmune diseases in mice including autoimmune diabetes, experimental arthritis, and other immune-mediated inflammatory diseases $[3,4]$.
CD39 is an ectoenzyme that hydrolyzes ATP and adenosine diphosphate (ADP) into adenosine monophosphate (AMP) and is localized on the surface of endothelial cells and circulating platelets. Now it is determined as an activation marker of lymphoid cells and expressed in human $\mathrm{CD}_{25}{ }^{+}$FoxP $^{+}$Treg cells [5]. CD39 has also been elucidated to be related to suppressive function of Treg $[6,7]$. Researches show that the expansion of $\mathrm{CD} 39^{+}$Treg inhibits IL-2 expression in activated T cells and correlates directly with immune activation in AIDS patients $[8,9]$. Adenosine deaminase (ADA) which is able to catabolize adenosine plays an obbligato role in CD39-CD73-adenosine pathway [10]. ADA deficiency may result in a fatal severe combined immunodeficiency disease (SCID) [11].

Runt-related transcription factor 1 (Runx1) belongs to a small family of transcription factors, including Runx1, Runx2, and Runx3, and is composed of an NH2-terminal DNAbinding runt homology domain followed by a transcriptional activation domain and $\mathrm{COOH}$-terminal negative regulatory 
domain $[12,13]$. The study with respect to Runxl has focused largely on its indispensable effect on FoxP3 expression and Treg function [14]. Knockdown of Runxl by siRNA eliminates the ability of Treg cells to suppress $\mathrm{T}$ effector cells in vitro [13]. A previous study demonstrates that the Runxl transcription factor plays a significant role in regulating ADA gene expression in the trophoblast cells [15].

Rapamycin has been demonstrated to be an immune modulator which prevents graft rejection in transplant patients $[16,17]$. Previous studies have shown that rapamycin improves the FoxP3 expression and selectively expands the functional Treg cells both in vivo and in vitro with the appropriate suppressive activity [18-21]. However, it is not clear that how rapamycin influences CD39 and Runxl pathways in human iTreg cells.

\section{Materials and Methods}

2.1. Isolation of Nä̈ve T Cells. Peripheral blood mononuclear cells (PBMCs) were prepared from heparinized venous blood of healthy adult volunteers by Ficoll-Hypaque density gradient centrifugation. All protocols that were involved in human blood donors were approved by Nanjing Medical University. $\mathrm{CD}^{+} \mathrm{CD}^{+} \mathrm{RA}^{+}$naïve T cells were isolated from PBMC with human naive $\mathrm{CD} 4^{+}$T-Cell Isolation Kit II (Miltenyi Biotec) by MACS. The purity of selected cells was routinely more than $95 \%$ as determined by flow cytometry.

2.2. Generation of Human iTreg Cells In Vitro. Fresh naïve T cells from PBMC were stimulated with anti-CD3/CD28 beads (Life Technologies) at a bead: T-cell ratio of $3: 1$ in the presence of IL-2 (100 U/mL), TGF- $\beta$ (10 ng/mL), and rapamycin $(100 \mathrm{ng} / \mathrm{mL})$ in different conditions. The concentration of naïve $\mathrm{T}$ cells was 0.5 million $/ \mathrm{mL}$ at the beginning. All the cells were incubated at $37^{\circ} \mathrm{C}$ for 7 days. IL-2 $(100 \mathrm{U} / \mathrm{mL})$ was renewed every 2 days.

2.3. Flow Cytometric Assays. All the cells were analyzed by flow cytometry after staining with the following antibodies (all from BD-Biosciences): anti-human CD4, CD25, CD28, CD39, and CD127. For FoxP3 staining, cells were first stained with surface antibodies, then fixed/permeabilized in cytofix/permeabilization solution (Biolegend), and stained with anti-human FoxP3.

2.4. Real-Time PCR. Total RNA was extracted with RNA simple total RNA kit (Tiangen Biotech), and cDNA was obtained using RT-Master Mix (TaKaRa). mRNA levels were quantified with SYBR Premix Ex Taq (TaKaRa). Primer sequences were as follows (18S as internal control):

$$
\begin{aligned}
& \text { ADA, } 5^{\prime} \text {-TTCCTTCCAAGAAGACCATGA-3' and } \\
& 5^{\prime} \text {-GGTTTCAGATTCAACCATGC-3'; } \\
& \text { Runx1, } 5^{\prime} \text {-GGACGCCAGAAGGAAGTCAA-3 }{ }^{\prime} \text { and } \\
& 5^{\prime} \text {-TCGGACCACAGAGCACTTTC-3 }{ }^{\prime} \text {; } \\
& \text { 18S, } 5^{\prime} \text {-CTCTTAGCTGAGTGTCCCGC-3' and } \\
& 5^{\prime} \text {-CTGATCGTCTTCGAACCTCC- } 3^{\prime} \text {. }
\end{aligned}
$$

2.5. Suppressive Assays of $\mathrm{CD}^{+}$Treg Cells In Vitro. PBMC was isolated as described previously and labeled with CFSE (Invitrogen). Anti-CD3 mAb-coated beads (Dynal) were added at 1:1 (bead:PBMC), and washed iTreg cells were added at ratios from 1:2 to 1:32 (Treg:PBMC). Finally cultures were incubated at $37^{\circ} \mathrm{C}$. On day 4, cells were stained with anti-CD8 APC. Data was acquired and analyzed using the proliferation platform in FlowJo, and suppression index was determined using division index.

2.6. Statistical Analysis. Statistical analysis was performed using GraphPad Prism 5.0 software. Data was presented as mean \pm SEM. Evaluation of differences between two groups was evaluated using Student's $t$-test. $P<0.05$ was considered as statistically significant difference.

\section{Results}

3.1. CD39 Expression in $\mathrm{CD}^{+} \mathrm{T}$ Cells in Human Peripheral Blood. A recent report shows that CD39 is related to T-cell proliferation and FoxP3 function [22]. However, whether CD39 plays an important role in maintaining human immunologic homeostasis is still unknown. To answer this question, initially, we evaluated the frequencies of CD39 in the human $\mathrm{CD}^{+} \mathrm{T}$ cells and Treg cells. Peripheral blood mononuclear cells (PBMCs) were isolated from 3 healthy donors, and the expression of CD4, CD25, CD39, and FoxP3 was analyzed by flow cytometry. Approximately $30 \%$ of $\mathrm{CD}^{+} \mathrm{T}$ cells were CD39 positive and these $\mathrm{CD} 4^{+} \mathrm{CD} 39^{+}$ $\mathrm{T}$ cells revealed an enhanced FoxP3 expression compared to $\mathrm{CD} 4^{+} \mathrm{CD} 39^{-} \mathrm{T}$ cells (Figure $1(\mathrm{a})$ ). Next, we gated on the $\mathrm{CD} 4{ }^{+} \mathrm{CD} 25^{+} \mathrm{FoxP}^{+}$Treg cells to calculate the CD39 expression in $\mathrm{CD}^{+} \mathrm{FoxP}^{+}{ }^{+}$T cells. As depicted in Figure 1(b), more than $70 \%$ of Treg cells were CD39 positive. Furthermore, FoxP3 expression was significantly distinct in $\mathrm{CD}^{+} 9^{+}$Treg cells compared to $\mathrm{CD} 39^{-}$cells. Figure 1(c) demonstrated the different proportion of the cells mentioned above. Here we conclude that CD39 is highly expressed in human FoxP3 ${ }^{+} \mathrm{T}$ cells and positively correlates with the FoxP3 expression in human peripheral blood.

3.2. The Addition of Rapamycin Improves the Expression of FoxP3 and Develops the Potent Suppressive Activity In Vitro. Naïve $\mathrm{CD}^{+} \mathrm{T}$ cells were cultured with suboptimal antiCD3/CD28 beads in the presence of IL-2, with or without TGF- $\beta$ and rapamycin for 7 days. While IL-2 and TGF$\beta$ increased the percentage of $\mathrm{CD}^{+} \mathrm{CD} 25^{+} \mathrm{FoxP}^{+} \mathrm{T}$ cells, the addition of rapamycin markedly enhanced this effect (Figures 2(a) and 2(b)). These data were consistent with previous studies, which showed that rapamycin favored Foxp3 expression and promoted the suppressive activity of iTreg cells [19-21, 23]. Then, we observed a distinct population of FoxP $3^{\text {high }}$ cells, which is defined as FoxP3 ${ }^{++}$ cells. The percentage of FoxP $3^{++}$iTreg cells was obviously increased from $13.6 \%$ to $27.8 \%$ in the presence of rapamycin (Figure 2(b)). The expression of CD25 was shown as the mean fluorescence intensity (MFI) for each culture condition which showed that rapamycin also enhanced CD25 expression 


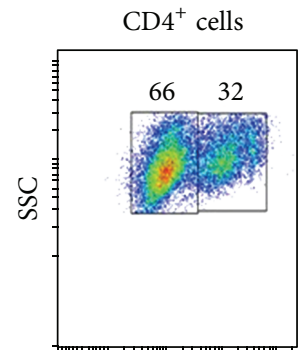

CD39

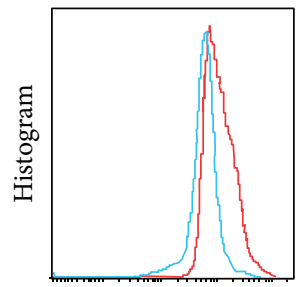

FoxP3

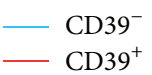

(a)
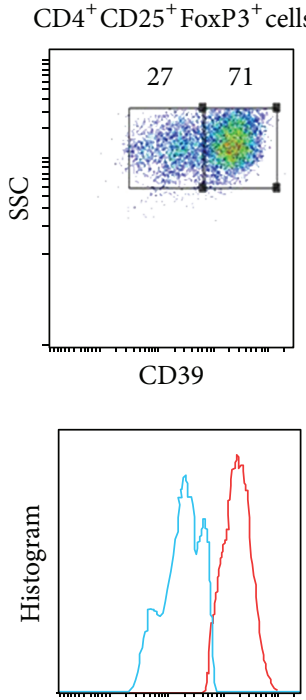

FoxP3

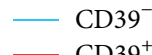

(b)

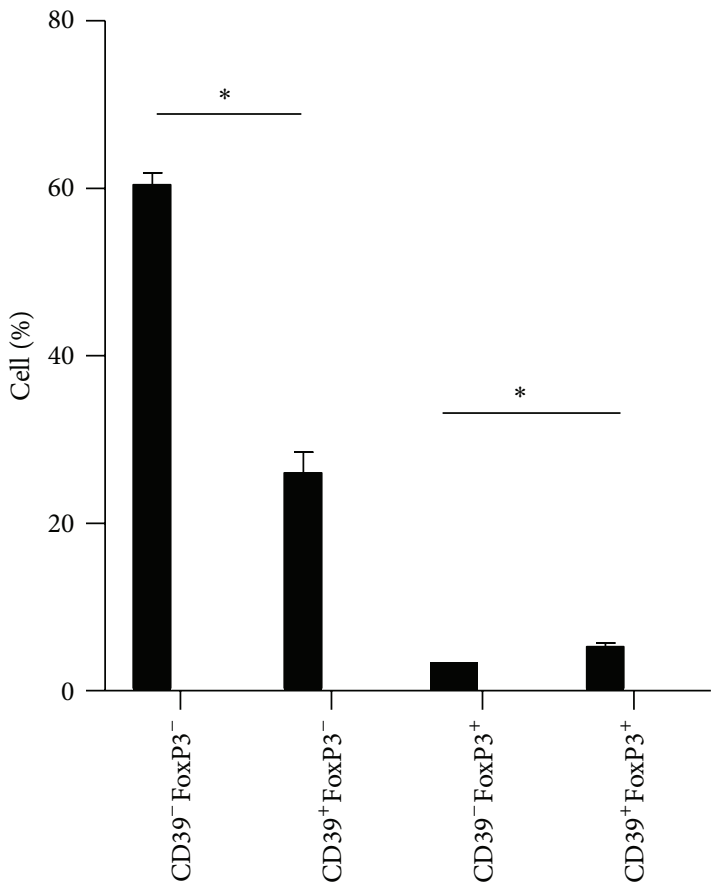

(c)

FIGURE 1: CD39 expression in human peripheral blood and nature FoxP3 cells. (a) Representative expression of CD39 gated in CD4 ${ }^{+} \mathrm{T}$ cells. (b) Representative expression of $\mathrm{CD} 39$ gated in $\mathrm{CD} 4^{+} \mathrm{CD} 25^{+} \mathrm{FoxP}^{+}$cells. (c) Different proportions of $\mathrm{CD} 39^{+}$and FoxP3 ${ }^{+}$cells in $\mathrm{CD} 4^{+} \mathrm{T}$ cells. The values indicated the mean \pm SEM of 3 separate experiments. ${ }^{*} P<0.05$.

in vitro (Figure 2(c)). Since the ability of cell suppression was important for the treating effect of iTreg cells, CFSE coculture assays were performed to estimate the suppressive ability of rapamycin-expanded Treg cells. Washed iTreg cells were coincubated with CFSE-labeled fresh PBMC in the presence of anti-CD3 beads. Although there was no significant difference between the iTreg cultured with or without rapamycin in low ratio $(1: 32)$, rapamycin did improve suppressive activity in high ratio (from $1: 2$ to $1: 8$ ) compared to IL-2 and TGF$\beta$ group (Figures 2(d) and 2(e)). On the whole, rapamycin improves the FoxP3 expression and enhances suppressive activity in vitro.

3.3. Rapamycin Improves CD39 Expression in iTreg Cells. As CD39 is important for the function of iTreg [24], next we evaluated the expression of CD39 in iTreg cultured in different conditions. TGF- $\beta$ enhanced the expression of CD39 from $14 \%$ to $62 \%$ compared with the group with IL2 alone, while the proportion ascended to nearly $70 \%$ with the addition of rapamycin (Figures 3(a) and 3(b)). CD39 MFI (Figure 3(c)) were also detected in these Treg cells which confirmed that the expression of CD39 and FoxP3 was positively correlated and enhanced by rapamycin. Therefore, we suggest that rapamycin improves CD39 expression in iTreg cells.

3.4. Rapamycin Upregulates ADA and Runx1 mRNA Level in iTreg Cells. ADA and Runxl play essential roles in FoxP3 expression and Treg function $[13,14,25]$. A previous study reveals that Runxl regulates ADA gene expression in the trophoblast cell line [15]. RT-PCR was performed to estimate the mRNA level of ADA; Figure 4(a) showed that the mRNA level of ADA was almost doubled in TGF- $\beta$ group compared to IL2 group and rapamycin slightly increased the ADA mRNA level. Next, we detected Runxl expression in the mRNA level, Figure 4(b) demonstrated that Runxl expression was increased approximately 3 -fold by TGF- $\beta$, and rapamycin obviously increased Runxl mRNA level. Since FoxP3 expression is controlled by Runxl [14], here we found that Runx1 expression was significantly enhanced by rapamycin. This observation suggests that rapamycin upregulates ADA and Runxl in human iTreg cell induction.

3.5. Phenotypic Characterization of Human $\mathrm{CD}^{+} 9^{+}$iTreg Cells. We elucidated that rapamycin promotes CD39 expression and then assumed that $\mathrm{CD}^{+} 9^{+}$iTreg cells might be a new subset of iTreg cells. To see phenotypic characterization of human $\mathrm{CD} 9^{+}$iTreg cells, we calculated MFI for CD25, FoxP3 in different Treg phenotypes. As shown in Figure 5(a), a stronger CD25 and FoxP3 expression was detected in $\mathrm{CD}^{+} 9^{+}$iTreg cells compared to $\mathrm{CD}^{-}{ }^{-}$iTreg in the same culture condition. In rapamycin group, the relative FoxP3 MFI in $\mathrm{CD}^{+} 9^{+}$iTreg was about 20\% higher than $\mathrm{CD}^{-} 9^{-}$iTreg. Since CD127 could be an effective surface marker for $\mathrm{CD} 4^{+} \mathrm{CD} 25^{+} \mathrm{FoxP}^{+}$Treg cells in flow sorting, we also determined the expression of CD39 in $\mathrm{CD} 4^{+} \mathrm{CD} 25^{+} \mathrm{CD} 127^{-}$iTreg cells. $\mathrm{CD} 4^{+} \mathrm{CD} 25^{+} \mathrm{CD} 39^{+} \mathrm{CD} 127^{-}$ 


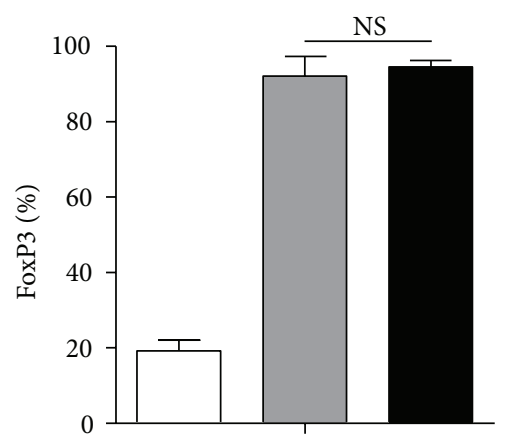

IL-2 only
믁 $\beta$
TGF- $\beta$ /rapa

(a)

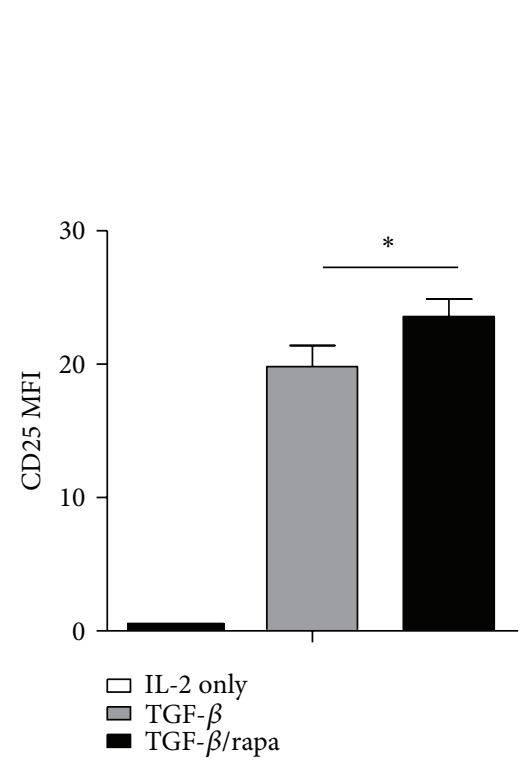

(c)

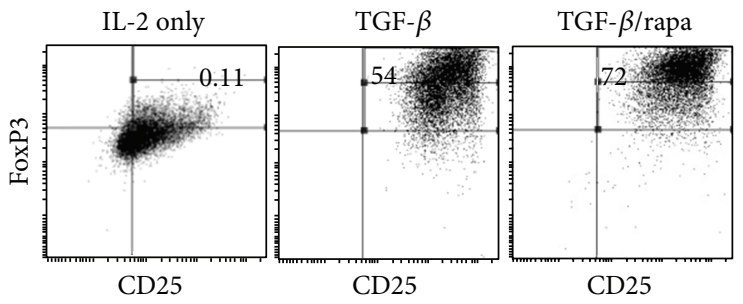

(b)
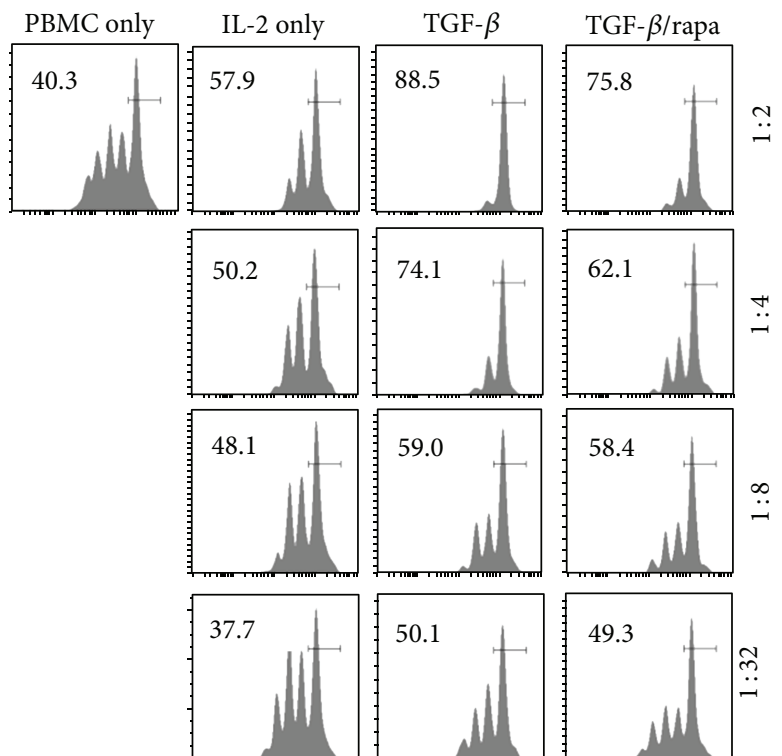

50.1
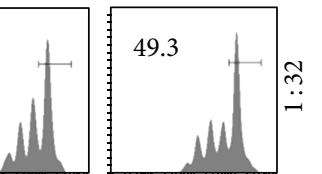

(d)

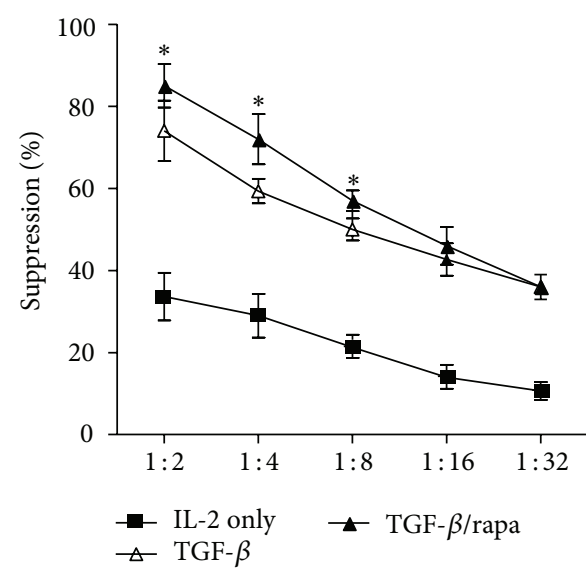

(e)

Figure 2: Rapamycin improved the expression of FoxP3 and developed the potent suppressive activity in vitro. (a) The proportion of $\mathrm{CD}^{+}{ }^{+} \mathrm{CD} 25^{+}$FoxP $3^{+}$iTreg induced from naïve T cells. (b) CD25 and FoxP3 coexpression in iTreg was assessed by flow cytometry on day 7. (c) Relative CD25 MFI in iTreg cells on day 7 with or without rapamycin. (d) In this representative experiment, the cells were stained for anti-CD8 and the suppressive activity of various primed $\mathrm{CD} 4^{+}$cells subsets on CFSE-labeled $\mathrm{CD} 8^{+}$at various $\mathrm{T}$ suppressor to $\mathrm{T}$ effector ratios was shown. (e) The mean \pm SEM percent suppression of iTreg at the various ratios. The values indicated the mean \pm SEM of 3 separate experiments. ${ }^{*} P<0.05$. 


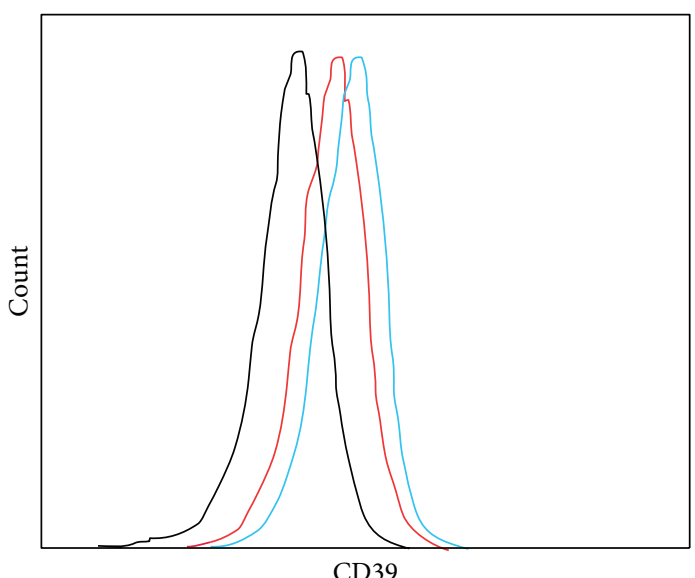

CD39

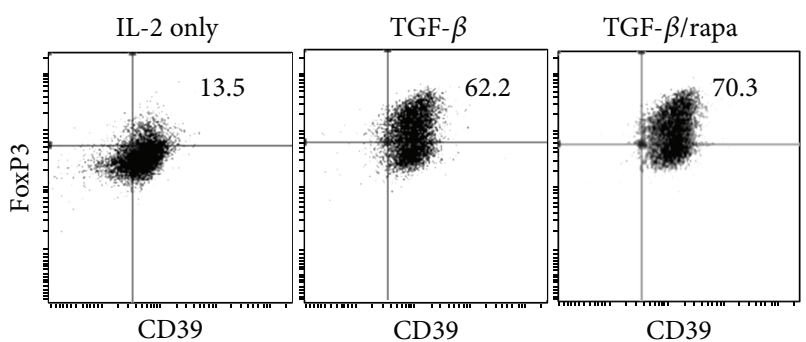

(b)

(a)

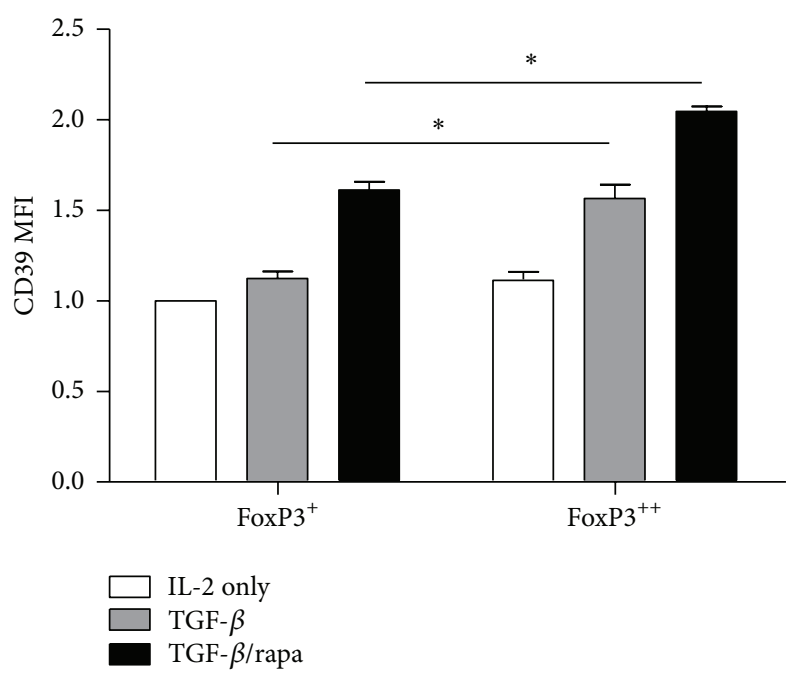

(c)

FIGURE 3: Rapamycin improved CD39 expression in iTreg cells. (a) Representative intensity of CD39 in iTreg cells. (b) FACS analysis of CD39 and FoxP3 expression with or without rapamycin was shown. (c) Relative CD39 MFI in FoxP3 ${ }^{+}$and FoxP3 ${ }^{++}$iTreg cells on day 7 with or without rapamycin. The values indicated the mean \pm SEM of 3 separate experiments. ${ }^{*} P<0.05$.

iTreg also showed a significant difference of FoxP3 and $\mathrm{CD} 25$ expression compared to $\mathrm{CD} 4^{+} \mathrm{CD} 25^{+} \mathrm{CD} 39^{-} \mathrm{CD} 127^{-}$ iTreg cells (Figure 5(b)), and the relative FoxP3 MFI in $\mathrm{CD} 4^{+} \mathrm{CD} 25^{+} \mathrm{CD} 39^{+} \mathrm{CD} 127^{-}$iTreg was also about $20 \%$ higher than $\mathrm{CD} 4^{+} \mathrm{CD} 25^{+} \mathrm{CD} 39^{-} \mathrm{CD} 127^{-}$iTreg. Taken together, we demonstrate that $\mathrm{CD} 4^{+} \mathrm{CD} 25^{+} \mathrm{CD} 39^{+} \mathrm{CD} 127^{-}$iTreg cells show a stronger FoxP3 expression and CD39 could be an additional marker for Treg cell sorting.

\section{Discussion}

CD39 is a newly determined Treg marker that relates to cell suppression [26]. CD39 ${ }^{+}$Treg subset mediates a higher suppression compared to control HIV patients [8, 27]. However, CD39 is also expressed in activated T cells [28]. Herein we proved that more than $30 \%$ of $\mathrm{CD}^{+} \mathrm{T}$ cells in human PBMC were $\mathrm{CD} 39$ positive, while $\mathrm{CD} 4^{+} \mathrm{CD} 39^{-}$iTreg cells showed a low frequency of FoxP3 compared to $\mathrm{CD} 4^{+} \mathrm{CD} 39^{+}$ iTreg. Thus, we demonstrate that CD39 is involved in FoxP3 expression and Treg cells in human $\mathrm{CD} 4{ }^{+} \mathrm{T}$ cells.

ATP inhibits the generation and function of regulatory $\mathrm{T}$ cells [29]. CD39 which plays a crucial role in immunological system by generating adenosine and removing ATP becomes a promising therapeutic target in oncology [5]. ADA is involved in this pathway and converts adenosine and deoxyadenosine into inosine and deoxyinosine. 


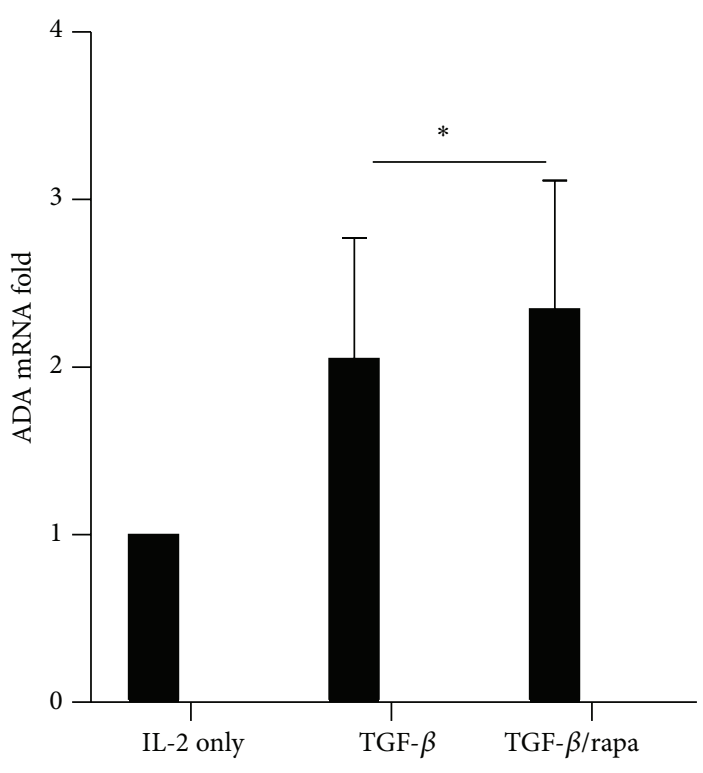

(a)

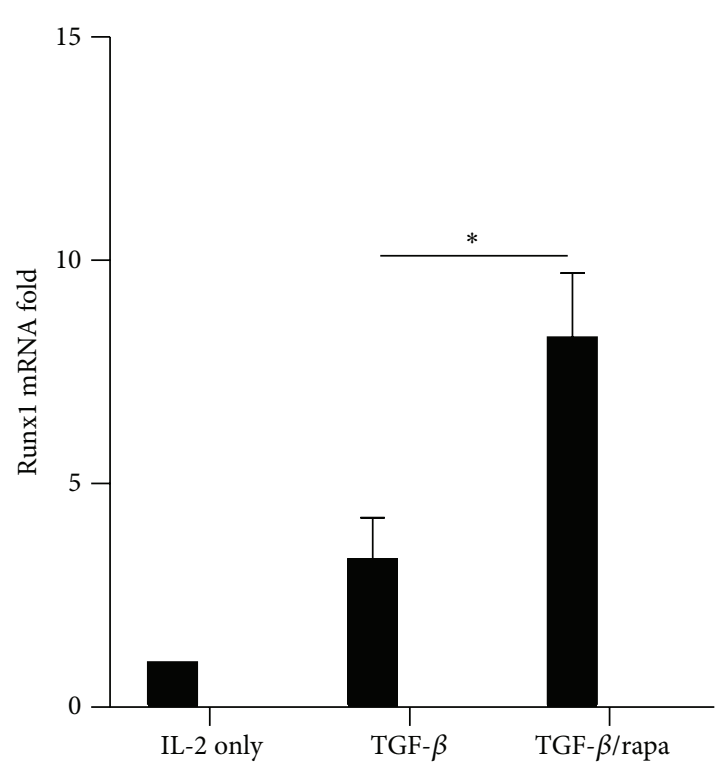

(b)

FIgURE 4: Rapamycin upregulated the mRNA level of ADA and Runxl in Treg cells. The expression of (a) ADA mRNA and (b) Runx1 mRNA was determined by RT-PCR. Gene expression levels from the IL-2 group were set at 1 . The values indicated the mean \pm SEM of 3 separate experiments. ${ }^{*} P<0.05$.

$\mathrm{CD} 4^{+} \mathrm{CD} 25^{\text {high }} \mathrm{T}$ cells express low level of ADA compared with effect T cells [30]. Adenosine and deoxyadenosine would accumulate in cells and then lead to ADASCID in the absence of ADA [25]. Thus, it might need a balanced metabolism of adenosine in Tregs because both overexpression and underexpression of ADA would cause Treg function unbalance. We demonstrate that rapamycin would obviously increase CD39 expression in iTreg cells and also enhance FoxP3 expression and suppressive function. A slightly enhanced ADA mRNA level was also observed in our study, which might be a positive feedback along with the increased CD39 expression. CD39/adenosine pathway is important to the balance of activation and regulation of effect immune responses. Since we found that $\mathrm{CD} 39^{+} \mathrm{CD} 127^{-}$ iTreg cells acquired a stronger FoxP3 expression compared to $\mathrm{CD}^{-} 9^{-} \mathrm{CD} 127^{-}$iTreg cells, it provides us with a new marker for novel strategy of flow cell sorting.

Rapamycin is an inhibitor of mTOR pathway, which is able to favor the proliferation of Treg cells [31]. Here we conclude that iTreg induced from naïve T cells would acquire an enhanced CD25 and FoxP3 expression in the presence of rapamycin.

Rapamycin promotes the demethylation of Treg cells in the TSDR region and improves FoxP3 expression and suppressive activity [32]. Runxl is also proved to be an unreplaceable gene which controls FoxP3 expression and Treg function $[13,33]$. Recently, Strober W's group discovered that ROR $\gamma$ t which is related to TH17 cells can also be induced by Runx1 [34]. Thus, Runx1 may have a complicated mechanism in balancing the generation of FoxP3 and IL-17 in human naive cells. We found that the number of FoxP3 $3^{++}$
Treg was greater in rapamycin group and Runxl expression was upregulated by rapamycin. It is consistent with the conclusion that rapamycin promotes FoxP3 expression and restrain IL-17 by altering expression of ROR $\gamma \mathrm{t}$ [35]. However, more researches are required to reveal the mechanism that how Runxl regulates Treg and Th17 cells.

Human Treg shows a great suppressive effect and stability in treating autoimmune disease. However, because of the limited amount of these cells in the blood, there are technical difficulties to expand their clinical usage. The welldescribed protective effect of $\mathrm{CD} 39^{+}$iTreg induced effectively by rapamycin provides us with a new strategy for Treg generation. Rapamycin greatly enhanced the expression of CD39 and Runx1. ADA, a promoter of CD39 pathway, can also be activated by rapamycin. Rapamycin treated CD $39^{+}$ iTreg may be an alternative choice which can be used for autoimmune disease treatment in vivo. Finally, we conclude that CD39 as a Treg function marker could provide us with new insights into clinical cell therapy in autoimmune diseases.

\section{Conclusion}

Our study indicated that the CD39 and Runxl signaling pathways were involved in the induction of human iTreg by rapamycin. Rapamycin enhanced the FoxP3 expression and suppressive activity of iTreg with the elevated ADA and Runx1 expression; CD39 correlated positively with FoxP3 expression which proved to be a promising marker for human Treg cell sorting. 

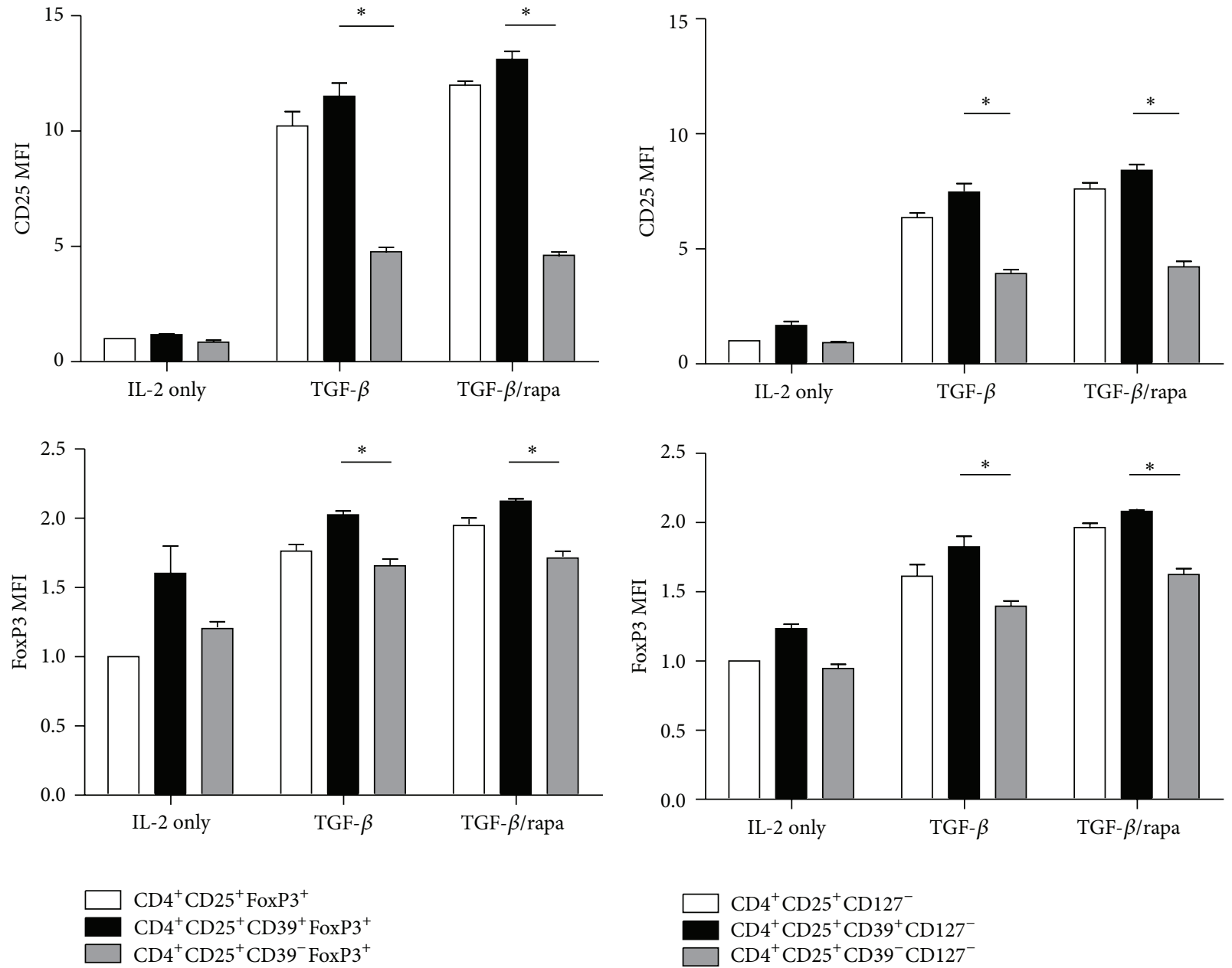

(a)

(b)

Figure 5: Rapamycin induced CD39 ${ }^{+}$iTreg cells showed a greater CD25 and FoxP3 expression. Relative CD25 and FoxP3 MFI of $\mathrm{CD}_{25}{ }^{+} \mathrm{CD} 39^{+} \mathrm{FoxP}^{+}$and $\mathrm{CD} 25^{+} \mathrm{CD} 39^{-} \mathrm{FoxP}^{+}$in (a) $\mathrm{CD}^{+} \mathrm{CD} 25^{+} \mathrm{FoxP}^{+}$iTreg cells and (b) $\mathrm{CD} 4^{+} \mathrm{CD} 25^{+} \mathrm{CD} 127^{-}$iTreg cells. The values indicated the mean \pm SEM of 3 separate experiments. ${ }^{*} P<0.05$.

\section{Conflict of Interests}

All the authors declare that they do not have any commercial or associative interest that represents a conflict of interests in connection with the work submitted.

\section{Authors' Contribution}

Yunjie $\mathrm{Lu}$ and Jirong Wang contributed equally to this work.

\section{Acknowledgments}

This study was supported by the International Collaboration Foundation of Jiangsu Province (BZ2011041, BK2009439, ZX05 200904, and WS2011106), the special funds of Ministry of Health for health research (201302009), Program for Development of Innovative Research Team in the First Affiliated Hospital of NJMU, and the National Nature Science
Foundation of China $(81273262,81210108017,81100270$, and 81070380).

\section{References}

[1] E. M. Shevach, "Mechanisms of Foxp3+ T regulatory cellmediated suppression," Immunity, vol. 30, no. 5, pp. 636-645, 2009.

[2] K. L. Hippen, S. C. Merkel, D. K. Schirm et al., "Generation and large-scale expansion of human inducible regulatory $\mathrm{T}$ cells that suppress graft-versus-host disease," American Journal of Transplantation, vol. 11, no. 6, pp. 1148-1157, 2011.

[3] J. F. Heiber and T. L. Geiger, "Context and location dependence of adaptive Foxp3(+) regulatory T cell formation during immunopathological conditions," Cellular Immunology, vol. 279, no. 1, pp. 60-65, 2012.

[4] N. Kong, Q. Lan, M. Chen et al., "Antigen-specific transforming growth factor beta-induced Treg cells, but not natural Treg cells, ameliorate autoimmune arthritis in mice by shifting the 
Th17/Treg cell balance from Th17 predominance to Treg cell predominance," Arthritis \& Rheumatism, vol. 64, no. 8, pp. 2548-2558, 2012.

[5] J. Bastid, A. Cottalorda-Regairaz, G. Alberici et al., "ENTPD1/CD39 is a promising therapeutic target in oncology," Oncogene, vol. 32, no. 14, pp. 1743-1751, 2013.

[6] P. J. Schuler, M. Harasymczuk, B. Schilling, S. Lang, and T. L. Whiteside, "Separation of human CD4+CD39+ T cells by magnetic beads reveals two phenotypically and functionally different subsets," Journal of Immunological Methods, vol. 369, no. 1-2, pp. 59-68, 2011.

[7] S. Deaglio, K. M. Dwyer, W. Gao et al., "Adenosine generation catalyzed by CD39 and CD73 expressed on regulatory $\mathrm{T}$ cells mediates immune suppression," Journal of Experimental Medicine, vol. 204, no. 6, pp. 1257-1265, 2007.

[8] M. Nikolova, M. Carriere, M. Jenabian et al., "CD39/adenosine pathway is involved in AIDS progression," PLoS Pathogens, vol. 7, no. 7, Article ID e1002110, 2011.

[9] M. A. Jenabian, N. Seddiki, A. Yatim et al., "Regulatory T cells negatively affect IL-2 production of effector T cells through CD39/adenosine pathway in HIV infection," PLOS Pathogens, vol. 9, no. 4, Article ID e1003319, 2013.

[10] M. Mandapathil, M. Szczepanski, M. Harasymczuk et al., "CD26 expression and adenosine deaminase activity in regulatory T cells (Treg) and CD4(+) T effector cells in patients with head and neck squamous cell carcinoma," Oncoimmunology, vol. 1, no. 5, pp. 659-669, 2012.

[11] R. Hirschhorn, "Adenosine deaminase deficiency," Immunodeficiency Reviews, vol. 2, no. 3, pp. 175-198, 1990.

[12] M. Kaczorowski and M. Jutel, "Human T regulatory cells: on the way to cognition," Archivum Immunologiae et Therapiae Experimentalis, vol. 61, no. 3, pp. 229-236, 2013.

[13] L. Bruno, L. Mazzarella, M. Hoogenkamp et al., "Runx proteins regulate Foxp3 expression," Journal of Experimental Medicine, vol. 206, no. 11, pp. 2329-2337, 2009.

[14] M. Ono, H. Yaguchi, N. Ohkura et al., "Foxp3 controls regulatory T-cell function by interacting with AML1/Runxl," Nature, vol. 446, no. 7136, pp. 685-689, 2007.

[15] B. M. Schaubach, H. Y. Wen, and R. E. Kellems, "Regulation of murine Ada gene expression in the placenta by transcription factor RUNX1," Placenta, vol. 27, no. 2-3, pp. 269-277, 2006.

[16] R. N. Saunders, M. S. Metcalfe, and M. L. Nicholson, "Rapamycin in transplantation: a review of the evidence," Kidney International, vol. 59, no. 1, pp. 3-16, 2001.

[17] H. Sugiyama, Y. Maeda, H. Nishimori et al., "Mammalian target of rapamycin inhibitors permit regulatory $\mathrm{T}$ cell reconstitution and inhibit experimental chronic graft-versus-host disease," Biology of Blood and Marrow Transplantation, vol. 20, no. 2, pp. 183-191, 2014.

[18] M. Battaglia, A. Stabilini, and M. Roncarolo, "Rapamycin selectively expands CD4+CD25+FoxP3 + regulatory T cells," Blood, vol. 105, no. 12, pp. 4743-4748, 2005.

[19] T. Zhao, C. Yang, Y. Qiu et al., "Comparison of regulatory T cells and FoxP3-positive T-cell subsets in the peripheral blood of renal transplant recipients with sirolimus versus cyclosporine: a preliminary study," Transplantation Proceedings, vol. 45, no. 1 , pp. 148-152, 2013.

[20] N. Prevel, Y. Allenbach, D. Klatzmann et al., "Beneficial role of rapamycin in experimental autoimmune myositis," PLoS ONE, vol. 8, no. 11, Article ID e74450, 2013.

[21] M. Donia, K. Mangano, A. Amoroso et al., "Treatment with rapamycin ameliorates clinical and histological signs of protracted relapsing experimental allergic encephalomyelitis in Dark Agouti rats and induces expansion of peripheral CD4+CD25+Foxp3+ regulatory T cells," Journal of Autoimmunity, vol. 33, no. 2, pp. 135-140, 2009.

[22] C. R. Grant, R. Liberal, B. S. Holder et al., "Dysfunctional CD39 regulatory $\mathrm{T}$ cells and aberrant control of $\mathrm{T}$ helper type 17 cells in autoimmune hepatitis," Hepatology, vol. 59, no. 3, pp. 10071015, 2014.

[23] R. Zeiser, D. B. Leveson-Gower, E. A. Zambricki et al., "Differential impact of mammalian target of rapamycin inhibition on CD4 +CD25+Foxp3+ regulatory $\mathrm{T}$ cells compared with conventional CD4+ T cells," Blood, vol. 111, no. 1, pp. 453-462, 2008.

[24] T. L. Whiteside, "Regulatory T cell subsets in human cancer: are they regulating for or against tumor progression?" Cancer Immunology, Immunotherapy, vol. 63, no. 1, pp. 67-72, 2014.

[25] A. V. Sauer, I. Brigida, N. Carriglio et al., "Alterations in the adenosine metabolism and CD39/CD73 adenosinergic machinery cause loss of Treg cell function and autoimmunity in ADAdeficient SCID," Blood, vol. 119, no. 6, pp. 1428-1439, 2012.

[26] G. Borsellino, M. Kleinewietfeld, D. Di Mitri et al., "Expression of ectonucleotidase CD39 by Foxp3+ Treg cells: hydrolysis of extracellular ATP and immune suppression," Blood, vol. 110, no. 4, pp. 1225-1232, 2007.

[27] M. Mandapathil, S. Lang, E. Gorelik, and T. L. Whiteside, "Isolation of functional human regulatory T cells (Treg) from the peripheral blood based on the CD39 expression," Journal of Immunological Methods, vol. 346, no. 1-2, pp. 55-63, 2009.

[28] M. S. Alam, C. C. Kurtz, R. M. Rowlett et al., "CD73 is expressed by human regulatory $\mathrm{T}$ helper cells and suppresses proinflammatory cytokine production and Helicobacter felisinduced gastritis in mice," Journal of Infectious Diseases, vol. 199, no. 4, pp. 494-504, 2009.

[29] U. Schenk, M. Frascoli, M. Proietti et al., "ATP inhibits the generation and function of regulatory $\mathrm{T}$ cells through the activation of purinergic P2X receptors," Science Signaling, vol. 4, no. 162, p. ra12, 2011.

[30] M. Mandapathil, B. Hilldorfer, M. J. Szczepanski et al., "Generation and accumulation of immunosuppressive adenosine by human CD4+CD25highFOXP3+ regulatory T Cells," Journal of Biological Chemistry, vol. 285, no. 10, pp. 7176-7186, 2010.

[31] M. Battaglia, A. Stabilini, B. Migliavacca, J. Horejs-Hoeck, T. Kaupper, and M. Roncarolo, "Rapamycin promotes expansion of functional $\mathrm{CD} 4+\mathrm{CD} 25+\mathrm{FOXP} 3+$ regulatory $\mathrm{T}$ cells of both healthy subjects and type 1 diabetic patients," Journal of Immunology, vol. 177, no. 12, pp. 8338-8347, 2006.

[32] T. Akimova, B. M. Kamath, J. W. Goebel et al., "Differing effects of rapamycin or calcineurin inhibitor on T-regulatory cells in pediatric liver and kidney transplant recipients," American Journal of Transplantation, vol. 12, no. 12, pp. 3449-3461, 2012.

[33] A. Kitoh, M. Ono, Y. Naoe et al., "Indispensable role of the Runx1-Cbf $\beta$ transcription complex for in vivo-suppressive function of FoxP3+ regulatory T cells," Immunity, vol. 31, no. 4, pp. 609-620, 2009.

[34] F. Zhang, G. Meng, and W. Strober, "Interactions among the transcription factors Runxl, ROR $\gamma$ t and Foxp3 regulate the differentiation of interleukin 17-producing T cells," Nature Immunology, vol. 9, no. 11, pp. 1297-1306, 2008.

[35] E. Yurchenko, M. T. Shio, T. C. Huang et al., "Inflammationdriven reprogramming of $\mathrm{CD} 4+$ foxp3+ regulatory $\mathrm{T}$ cells into pathogenic Th1/Th17 $\mathrm{t}$ effectors is abrogated by mTOR inhibition in vivo," PLoS ONE, vol. 7, no. 4, Article ID e35572, 2012. 


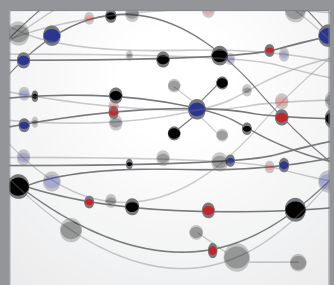

The Scientific World Journal
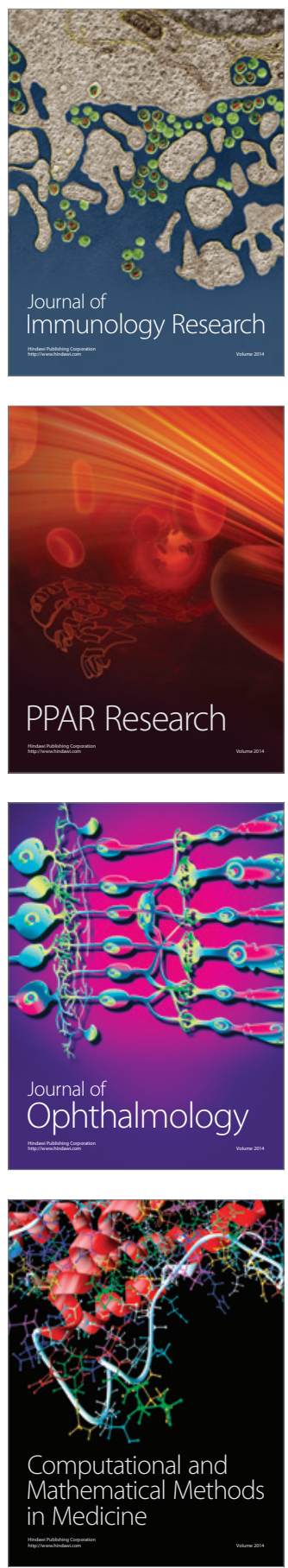

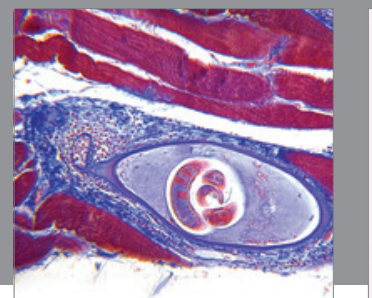

Gastroenterology

Research and Practice
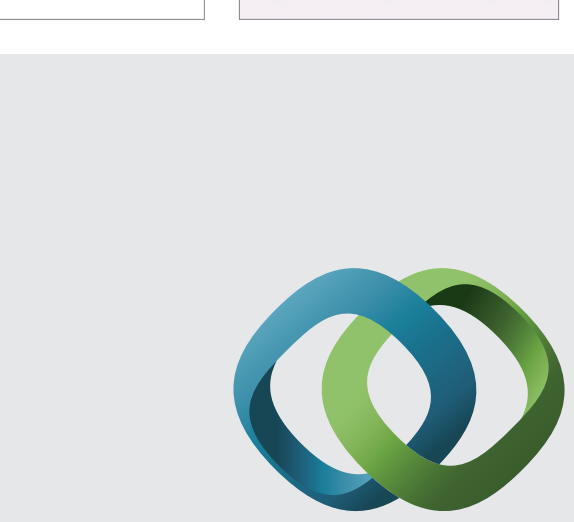

\section{Hindawi}

Submit your manuscripts at

http://www.hindawi.com
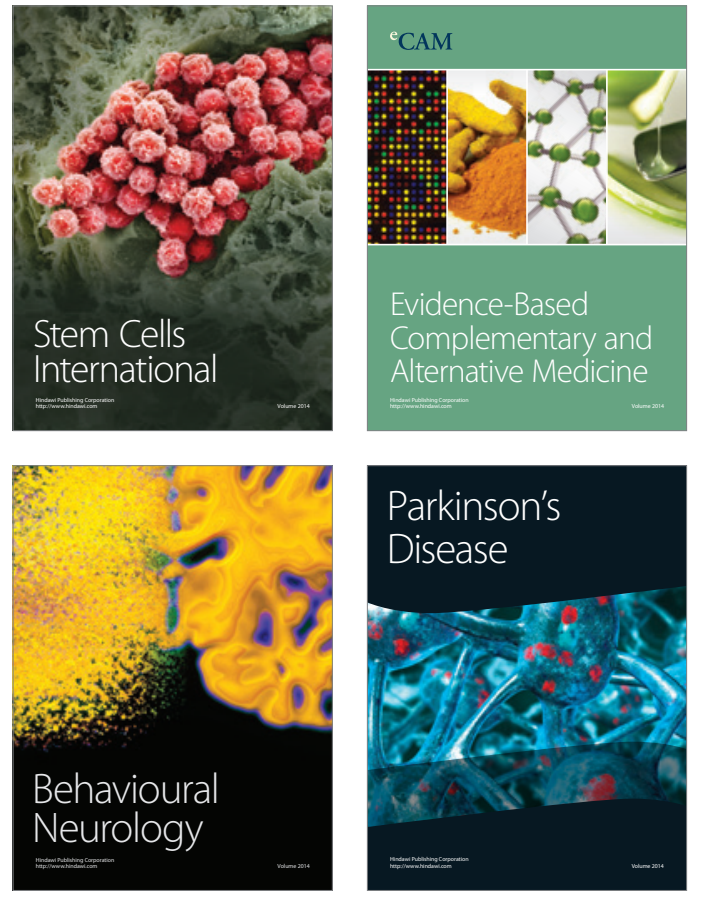
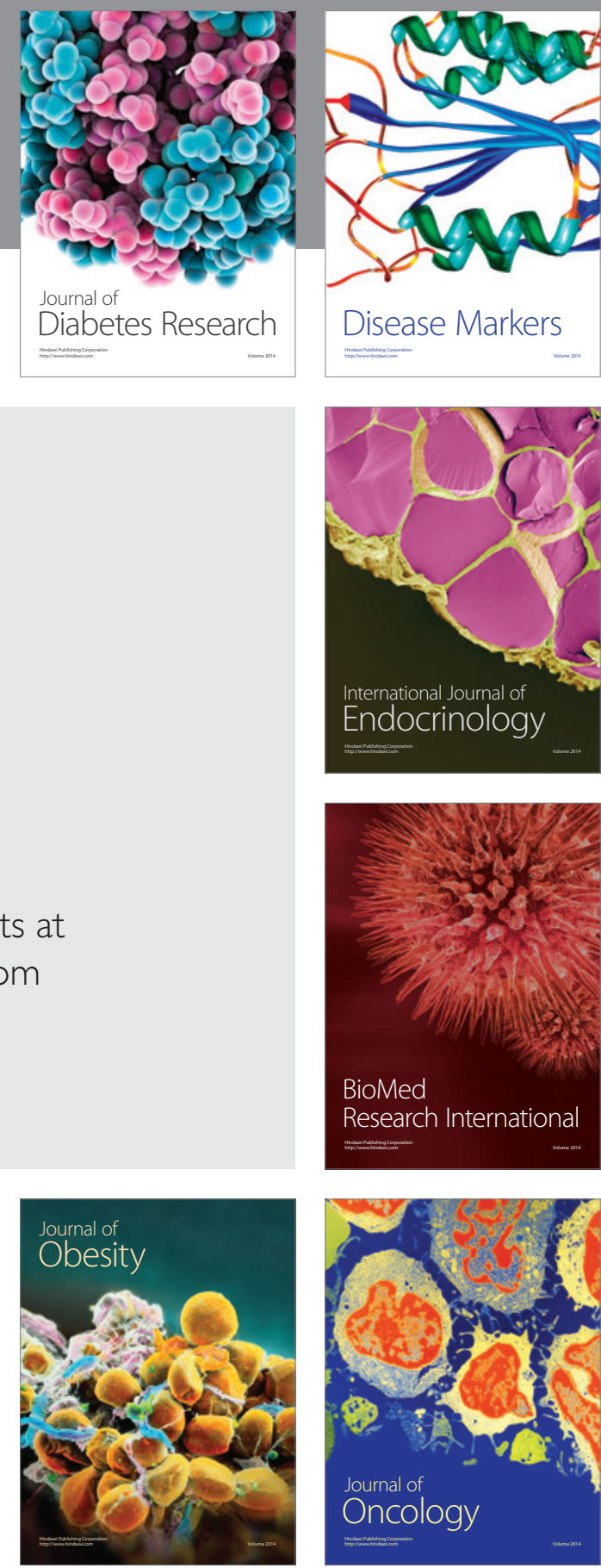

Disease Markers
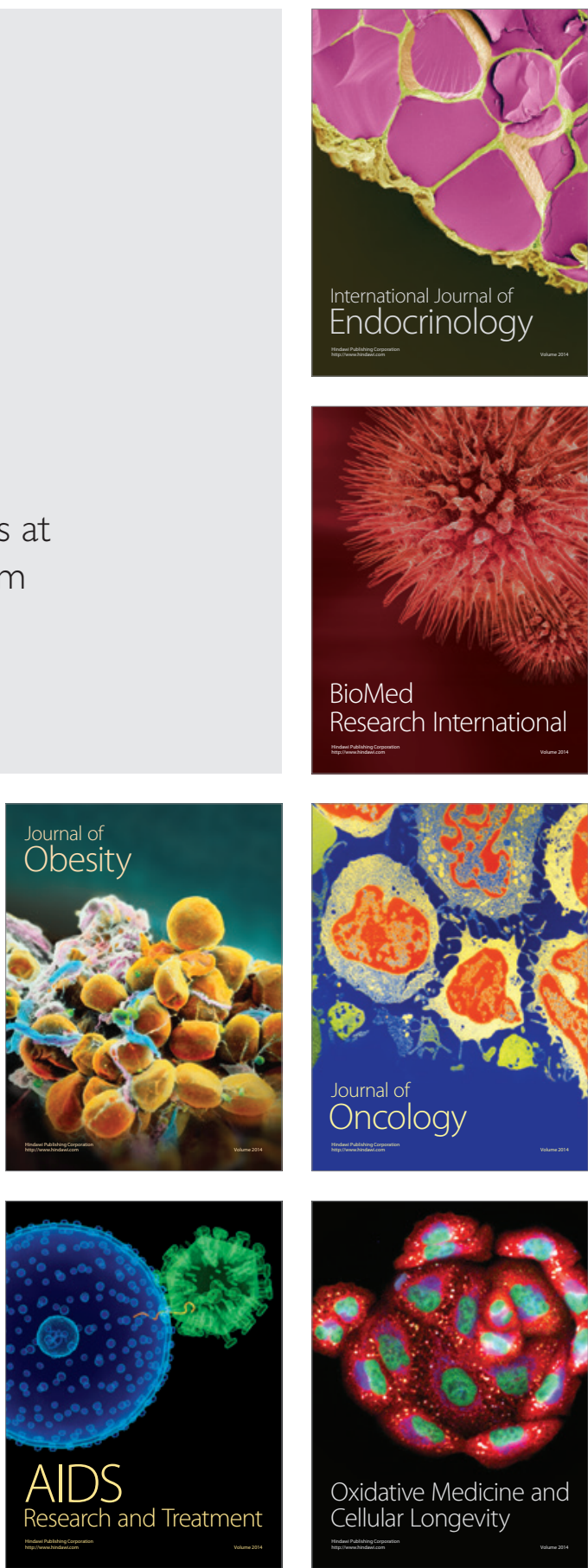